\title{
59
}

\section{Teaching Engineering Technology with the World Wide Web}

\author{
Derral R. Linder \\ Orangeburg-Calhoun Technical College \\ 3250 St. Matthews Road \\ Orangeburg, SC 29118-8299 \\ Phone: (803) 535-1294 \\ Fax: (803) 535-1388 \\ E-mail: linderd@org.tec.sc.us
}

\begin{abstract}
The Mechanical Engineering Department at Orangeburg-Calhoun Technical College has begun using the World Wide Web as an information source to supplement information presented to students. This instruction is currently being done in three ways. First, students are required to use at least three documents from the web when writing research papers for Mechanical Engineering Technology courses. Second, instructors research the web for examples that may be more current than examples given in the text. The URL's of these examples are then given to the students and homework assignments based on these examples are assigned. Third, students are expected to use the Internet to prepare parts lists and to find information about manufacturing companies. At the end of the first year of exposure to the World Wide Web, graduates are experiencing unusual rewards for their work.
\end{abstract}

World Wide Web, Internet, URL

\section{Keywords}

\section{INTRODUCTION}

With today's ever tightening educational budgets from local, state and federal governments, it is essential that colleges and universities reduce their operating expenses. One area where costs are skyrocketing is resource materials that must 
keep pace with ever changing technology. In many cases, students are forced to use material that may be as much as twenty to thirty years out of date as colleges can no longer afford to replenish resource materials. There is one very practical way that is used here at Orangeburg-Calhoun Technical College (OCTC) to combat the high cost of resource materials - the Internet. OCTC has had access for nearly two years and is the only two year college in the state that presently offers more than one accredited course in the use of the Internet. For students in the Mechanical Engineering Technology (MET) department a workshop on the use of the Internet is mandatory.

\section{CLASSROOM PROCEDURES}

\section{Student Indoctrination}

Many students who come to OCTC do not have any prior experience with using the Internet so they may not be able to use the net immediately. This presents no problems to any student entering the college, as OCTC is the first and presently the only two year institution in South Carolina offering more than one course for credit to teach the student how to function on the web. These courses are IST 225, IST 226, IST 227 and IST 228 . IST 225 is the introductory course and offers topics associated with the Internet and Internet communications such as techniques on how to access various types of information, how to find resources and how to navigate the Internet. The course also introduces the students to E-mail and how they may set up their own web page. Presently, there is no account available for either student E-mail or web sites. Due to resource limitations, the college is unable to provide accounts for students. IST 225 is offered as an elective to all students and the response is so great that it is usually filled by the end of the first week of pre-registration (Hulsey, 1996). Also, students who take all four courses are finding employment as Web Masters earning as much as forty dollars per hour in the Orangeburg area. Students in the MET department are offered IST 225 as an elective but they are also required to attend a three hour workshop taught by the department head on using the Internet. This workshop is mandatory for MET seniors, but students from other curriculums are welcome to attend. It is offered several times a semester for student convenience. It teaches students how to access the web, open files if the URL is known and to use search engines, primarily, Excite, Savvy Search, Yahoo and HotBot. Once the students have attended the workshop, they are then given assignments to complete using the web.

\section{Student Assignments}

Student assignments are usually broken down into three broad categories. The first category involves the professor finding a suitable web page or article beforehand and giving the URL to the students and requiring that a report be written on the article. The next category is the old fashion research paper, and the final is for students to research the net for information concerning manufacturers. These 
assignments are usually given in the order listed to facilitate the students development as they learn to navigate the web.

An example of the first category is that during the first week of MET 222, (Thermodynamics), one class discussion centers on temperature, the different temperature scales used, history of temperature measurement, absolute temperature and the effects of temperature on some environment. The students are given the following URL:

\section{http://www.unidata.ucar.edu/staff/blynds/tmp.html}

This address opens an excellent article about temperature and the students write a five hundred word summary on the article complete with keywords and abstract. The purpose of this assignment is three fold. It gives the students an opportunity to open a website using a known URL, refresh skills learned in the English and Technical Writing courses and to learn something about temperature.

As everyone knows, students everywhere love writing research papers. MET students are given a topic, length the paper must be in number of words or number of page., the number of resources to be cited and are asked to write a paper. Presently, at least half of the required number of resources must come from the Internet. The students use a search engine(s) to find materials related to the topic and are allowed to print one copy for their personal use in completing the paper. This is permitted along the same grounds that a student is allowed to make one copy of reference material for their personal use when using material that is closely guarded in the campus library. MET 231, (Machine Design), students are given the topic 'Engineering Ethics' and are expected to complete a fifteen hundred word research paper with a minimum of four references. Students usually find more than the required four references for this topic on the net and often use only these without going to the campus library for additional resources which gives rise to an issue that may need future discussion: Should students be allowed to find all the required resources on the web or should they be required to find some from traditional places such as the campus library? The MET department head has no problem with students using the web exclusively. The belief is that students will benefit more from using the Internet because the Internet is being used more often in places of employment. In addition, it is a concentrated source of information and does not require travel time to other facilities for research purposes. Although, not every instructor agrees with this view point, the MET department believes it is a valid one.

Finally students are required to use the Internet to find information about different manufacturing companies that have sites on the web. In MET 224 (Hydraulics and Pneumatics), the students are required to develop a list of vendors for a particular hydraulic or pneumatic equipment. This is not a new assignment as students have always been required to develop a vendor list from materials in the campus library such as the Thomas Registry. One particular aspect of this assignment is that there can be no repeat vendors in the class, which not only forces the students to use the web but also forces them to communicate with each other. In another assignment used in PHY 201 (Physics), students are given an engine's RPM, transmission gear ratio, differential gear ratio and tire 
specifications, i.e., LT265/75R16. The students then go to the Internet, search for a tire company page and find the tire diameter based on the specification. With this information, the student should be able to calculate the speed of the automobile in miles per hour. A future enhancement of this assignment may be to give the student the make of a particular vehicle, i.e., Ford Mustang GT along with the engine RPM and have them find all the information about the vehicle including gear ratios and tire specifications before calculating the speed of the automobile.

This final category of assignment is probably the most beneficial to the student. Once students leave OCTC and begin working, they often find themselves in positions where they must purchase supplies, equipment or gather information about a customer or even a competitor. If the students already have a background in using the Internet to search for such materials, this portion of their job will be easier.

\section{INSTRUCTOR PREPARATION}

Professors and instructors typically spend more time preparing for classes than they do actually teaching the class. This is true even if they teach the same course more than once per semester. The internet offers a distinct advantage for instructors that may considerably reduce preparation time. Many colleges and universities have home pages on the web and many departments within those institutions have a web page. Orangeburg-Calhoun Technical College may be visited at: http://www.octech.org. The URL of most colleges can be found at: http://www.mit.edu:8001/people/cdemello/univ.html.

Information posted on these pages may contain courses required for completion of the program and many times contain course outlines and syllabi as well. This readily accessible information allows an instructor to review many different ways of administering any given course and possibly select methods that may be better than the method previously used.

Also, laboratory experiments can be very expensive and often require extensive equipment which many colleges can no longer afford. Therefore, instructors at OCTC are currently searching the net to find alternative methods of providing labs. For example, early in MET 222 the perfect gas laws are taught. The instructor found very inexpensive methods of providing laboratory experiments to prove both Charles and Boyle's laws at: http:/www.gp.k12.mi.us:80/main/schools/high/gpn/science/exp/exp.htm. These experiments were adopted for the laboratory sections of the class.

\section{DOCUMENTATION OF RESOURCES}

The faculty and administration at OCTC consider all material on the web to be copyrighted unless the material states otherwise. Therefore, all material taken from the Internet, either by student or professor, must be properly documented. The MET department at OCTC currently uses the following method (Perrin): 
Author's name (if known), the full title of the article in quotations, the title of the complete work, if applicable, in italics, the date of the visit, and the complete URL.

EXAMPLE: Beverly T. Lynds, "About Temperature," Oct. 10, 1996, http://www.unidata.ucar.edu/staff/blynds/tmp.html.

\section{CONCLUSIONS}

The MET department has been requiring students to learn to use the Internet for two years and has had some very positive results. Students enjoy 'surfing the net' much more so than going to the campus library and have even used the web as a resource in classes where using the web is not required. One non-engineering class MET students are required to take is (HSS 101), Introduction to Humanities. Students in this course are required to write several papers based on cultural events and have started using the net to find information. Students have also found that the web can be used as a source to search for prospective employers in other areas of the country or world. The MET department considers the students' enthusiasm and quickly acquired expertise as a success in the program of using the web as a learning resource. Also, two very unique successes of the program have arisen. First, one graduating senior was selected over several four year graduates because the student could assemble parts and vendor list rather easily from the web. The other graduate is now managing a farm and is using the Internet to monitor the commodity market and weather in order to make more informed decisions on what and when to plant, when to harvest crops and when to buy and sell livestock.

The MET department is planning to expand the use of the Internet in the classroom. The MET home page is expected to be on-line by the 1997 fall semester and will be used as an aid in recruitment of students. Another plan for next year is to post tests on the MET page and have students complete them cooperatively. The students would then E-mail the results back to the professor for grading which will allow more time for class room and lab instruction..

\section{REFERENCES}

Hulsey, D. (1996), IST 225 Internet, OCTC Course Outline.

Perrin, R. (1997), The Beacon Handbook, 4th. Edition, Houghton Mifflin, New York.

\section{BIOGRAPHY}

Derral R. Linder holds a master's degree in Industrial Engineering and a bachelor's degree in Mechanical Engineering Technology from Clemson University as well as an associate's degree in MET from OCTC. He is the MET department head at OCTC having held that position for three years. During this time he has been instrumental in pioneering student use of the Internet at the college. Prior to this 
position, Mr. Linder worked in industry in various engineering functions including designer, process and quality engineering and engineering supervisor. 